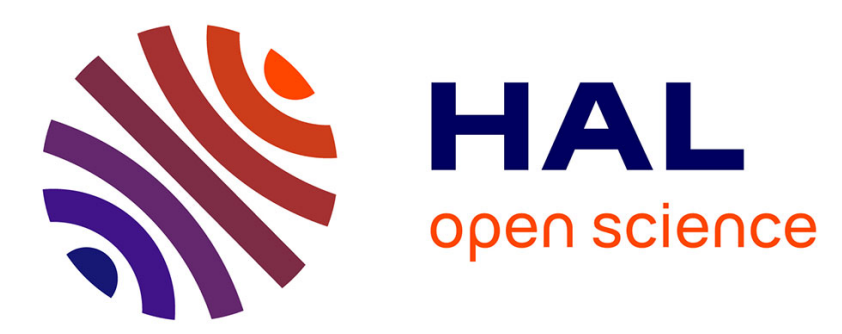

\title{
From the infrared to the visible range: Spectroscopic studies of ytterbium doped oxyborates
}

Veronique Jubera, Jean Sablayrolles, François Guillen, Rodolphe Decourt, Michel Couzi, Alain Garcia

\section{- To cite this version:}

Veronique Jubera, Jean Sablayrolles, François Guillen, Rodolphe Decourt, Michel Couzi, et al.. From the infrared to the visible range: Spectroscopic studies of ytterbium doped oxyborates. Optics Communications, 2009, 282 (1), pp.53-59. 10.1016/j.optcom.2008.09.075 . hal-00339966

\section{HAL Id: hal-00339966 https://hal.science/hal-00339966}

Submitted on 15 Feb 2012

HAL is a multi-disciplinary open access archive for the deposit and dissemination of scientific research documents, whether they are published or not. The documents may come from teaching and research institutions in France or abroad, or from public or private research centers.
L'archive ouverte pluridisciplinaire HAL, est destinée au dépôt et à la diffusion de documents scientifiques de niveau recherche, publiés ou non, émanant des établissements d'enseignement et de recherche français ou étrangers, des laboratoires publics ou privés. 


\title{
From the infrared to the visible range: Spectroscopic studies of ytterbium doped oxyborates
}

Jubera V., Sablayrolles J., Guillen F., Decourt R., Couzi M., Garcia A.

Published in Optics Communications 2009, vol. 282, $\mathrm{n}^{\circ}$ 1, p. 53-59.

\begin{abstract}
The spectroscopic study of yttrium oxyborates doped with trivalent ytterbium is conducted in the UV-Visible and infrared range. The multiplicity of the ytterbium environments in the studied compounds leads to complex emission spectra in the infrared and excitation spectra in the ultraviolet. Different ${ }^{2} \mathrm{~F}_{5 / 2}$ and ${ }^{2} \mathrm{~F}_{7 / 2}$ transitions have been pointed out. The emission extends up to $1090 \mathrm{~nm}$ for one compound. A correlation was evidenced between position and deexcitation mode of a charge transfer band and ytterbium environment for both oxyborates. Decay time dependence as a function of ytterbium concentration is also reported. For the highest concentration, a blue-green luminescence can be observed under strong IR excitation. Its study revealed two possible mechanisms: erbium ion emission at $550 \mathrm{~nm}$ after up-conversion and cooperative luminescence of ytterbium ions.
\end{abstract}

\section{Introduction :}

In the last decade, more attention has been devoted to the ytterbium doped materials. A direct excitation in the $4 \mathrm{f}-4 \mathrm{f}$ absorption line of the rare earth (RE) ion is possible with commercialized semi-conductor diodes. The infrared emission between $4 \mathrm{f}$ levels of the ytterbium ion has been studied in many crystals because of its applications in all-solid-state lasers operating in continuous or pulsed fashion (non exhaustive list [1], [2], [3], [4], [5], [6] and [7]). The laser effect, obtained by stimulated emission depends on spectroscopic properties. The knowledge of these characteristics can help to predict the potentiality of the material. The ytterbium ion possesses only two spectroscopic terms $\left({ }^{2} F_{7 / 2}\right.$ for the ground state and ${ }^{2} \mathrm{~F}_{5 / 2}$ for the excited state) split by the crystal field in 4 and 3 Stark levels, respectively. This perturbation leads to levels separated by several hundreds of $\mathrm{cm}^{-1}$. This is why at room temperature the Stark levels are thermally populated increasing the number of electronic transitions on absorption and emission spectra. Moreover, the ytterbium ion leads to vibronic transitions due to its high electron-phonon coupling [8]. Another characteristic of the ytterbium ion is the re-absorption of the infrared fluorescence due to the overlap between absorption and emission spectra. This phenomenon influences the lifetime value when the concentration increases. Finally, under high infrared laser excitation, ytterbium doped crystal or powder can exhibit a blue-green luminescence.

These different characteristics have been studied here on two ytterbium doped oxyborate compounds: $\mathrm{LiY}_{6} \mathrm{O}_{5}\left(\mathrm{BO}_{3}\right)_{3}$ and $\mathrm{Y}_{17.33} \mathrm{O}_{16}\left(\mathrm{BO}_{3}\right)_{4}\left(\mathrm{~B}_{2} \mathrm{O}_{5}\right)_{2}\left(\mathrm{Y}_{17.33} \mathrm{~B}_{8} \mathrm{O}_{38}\right)$. The luminescence is reported in the infrared and visible range.

\section{Experimental :}

\subsection{Sample preparation}

Solid solution powders of the rare earth oxide (purity $\geqslant 99.99 \%$ ) were previously prepared by dissolution in concentrated nitric acid in order to obtain a homogeneous distribution of the constituents, then the solutions were evaporated to dryness and fired in order to eliminate nitric vapor. The crystalline powders of $\mathrm{LiY}_{6} \mathrm{O}_{5}\left(\mathrm{BO}_{3}\right)_{3}: \mathrm{Yb}^{3+}[9]$ and [10] and $\mathrm{Y}_{17.33} \mathrm{O}_{16}\left(\mathrm{BO}_{3}\right)_{4}\left(\mathrm{~B}_{2} \mathrm{O}_{5}\right)_{2}\left(\mathrm{Y}_{17.33} \mathrm{~B}_{8} \mathrm{O}_{38}\right)$ [11] were synthesized by solid state reaction at $450{ }^{\circ} \mathrm{C}$ for $2 \mathrm{~h}$ and then $900^{\circ} \mathrm{C}$ and $1100^{\circ} \mathrm{C}$ respectively during $15 \mathrm{~h}$, using the reactants in stoichiometric proportions following the reactions: 


$$
\begin{aligned}
& \mathrm{LiBO}_{2}+2 \mathrm{H}_{3} \mathrm{BO}_{3}+3 \mathrm{Y}_{2(1-x)} \mathrm{Ln}_{2 x} \mathrm{O}_{3} \\
& \quad \rightarrow \mathrm{LiY}_{6(1-x)} \mathrm{Ln}_{6 x} \mathrm{O}_{5}\left(\mathrm{BO}_{3}\right)_{3}+3 \mathrm{H}_{2} \mathrm{O} \uparrow \\
& 16 \mathrm{H}_{3} \mathrm{BO}_{3}+17.33 \mathrm{Y}_{2(1-x)} \mathrm{Ln}_{2 x} \mathrm{O}_{3} \\
& \quad \rightarrow 2 \mathrm{Y}_{1733(1-x)} \mathrm{Ln}_{1733 x} \mathrm{~B}_{8} \mathrm{O}_{38}+24 \mathrm{H}_{2} \mathrm{O} \uparrow
\end{aligned}
$$

The final products were controlled by X-ray diffraction on a Philips PW 1820 diffractometer with copper anode radiations.

\subsection{Experimental setup}

The emission spectra were recorded using a spectrofluorimeter (Edinburgh Instruments FL 900 CDT) with a M30 monochromator connected to a germanium AD403L detector for infrared emission and a PM Hamamatsu R955 for visible detection. A Xe lamp or a laser diode was used as excitation source.

Absorption and emission spectra at low temperature measurements were recorded on the previously described spectrometers equipped with an OPTISTAT cryostat (Oxford Instrument) cooled by liquid helium.

Infrared lifetime measurements were performed with a digital oscilloscope (LeCroy Waverunner LT 342) equipped with a germanium AD403HS detector coupled to a HR640 monochormator (Horiba Jobin-Yvon). Self-made Labview program was used for piloting the experiments.

Emission lifetimes in the visible range were recorded on an intensified CCD camera (Andor Technology). The excitation source for both measurements was an OPO (GWU355SH) pumped with a YAG:Nd $10 \mathrm{~Hz}$ continuum Surelite laser.

Raman measurements of the borate samples were recorded using a Raman spectrometer (LabRam Dilor) equipped with a CCD detector and connected to an Ar laser source (spectra physics 2030 model), with an emission at $514.5 \mathrm{~nm}$.

\subsection{Structural description}

The rare earth ions present complex environments. These two compounds possess several independent crystallographic sites for the rare earth element:

(i) in the matrix $\mathrm{LiY}_{6} \mathrm{O}_{5}\left(\mathrm{BO}_{3}\right)_{3}$, the rare earth cation is sevenfold (four different polyhedra) or eightfold (two types of polyhedra) coordinated to oxygen atoms,

(ii) the literature indicates coordination spheres of seven oxygen anions (seven different polyhedra) or nine oxygen anions (two sites) for the rare earth element in the $\mathrm{Y}_{17.33} \mathrm{~B}_{8} \mathrm{O}_{38}$ oxyborate.

Two kinds of oxygen atoms can also be distinguished: bridging atoms which belong to the borate anionic groups $\left(\mathrm{BO}_{3}\right)^{3-}$ or $\left(\mathrm{B}_{2} \mathrm{O}_{5}\right)^{4-}$ and non-bridging atoms located in $\mathrm{ORE}_{4}$ tetrahedra $(\mathrm{RE}=\mathrm{Y}, \mathrm{Yb})$.

\section{Results and discussion}

\subsection{Vibrational spectroscopy: IR and Raman spectra}

The infrared and Raman spectra recorded on powder samples are shown on Fig. 1. The vibrations peaks located below $500 \mathrm{~cm}^{-1}$ correspond to external modes of the matrices [12]. Prohibited transition in Raman or infrared spectroscopy can be distinguished due to the distortion of the environments. Position and vibration modes were attributed according to what is reported in the literature [13] and [14]. The free borate group $\left(\mathrm{BO}_{3}\right)^{3-}$ possesses a planar $D_{3 h}$ symmetry. The $v_{1}$ mode associated with the stretching of the $\mathrm{B} \leftrightarrow \mathrm{O}$ bonds in the plane is a singlet mode. Consequently, the splitting of this mode must correspond to a mode coupling in the unit cell and probably to several types of borate groups as well. All the Raman spectra show distinctly different components of the $v_{1}$ vibrations of the borate groups for both compounds. Although all expected $v_{1}$ components cannot be distinguished, the complexity of the Raman spectra in this frequency range is rather well correlated with the number of borate groups contained in the unit cell.

In the compound $\mathrm{LiY}_{6} \mathrm{O}_{5}\left(\mathrm{BO}_{3}\right)_{3}$, these vibration lines are located at $935 \mathrm{~cm}^{-1}$ and $950 \mathrm{~cm}^{-1}$. The Raman vibration peaks and infrared absorption lines are reported on Table 1 for $\mathrm{LiY}_{6} \mathrm{O}_{5}\left(\mathrm{BO}_{3}\right)_{3}$. 
The infrared and Raman spectra of the oxyborate $\mathrm{Y}_{17.33} \mathrm{O}_{16}\left(\mathrm{BO}_{3}\right)_{4}\left(\mathrm{~B}_{2} \mathrm{O}_{5}\right)_{2}$ present intense vibrations related with the $\left(\mathrm{BO}_{3}\right)^{3-}$ groups at $915 \mathrm{~cm}^{-1}$ and $925 \mathrm{~cm}^{-1}$. Absorption bands associated with the B-O-B stretching mode of the $\left(\mathrm{B}_{2} \mathrm{O}_{5}\right)^{4-}$ group are located at $858 \mathrm{~cm}^{-1}$ on the infrared curve. The bands corresponding to $\left(\mathrm{BO}_{2}\right)^{2-}$ groups are located at $1054 \mathrm{~cm}^{-1}$ on both spectra. By comparison with the compound $\mathrm{LiY}_{6} \mathrm{O}_{5}\left(\mathrm{BO}_{3}\right)_{3}$, the $v_{2}, v_{3}$ and $v_{4}$ transitions of $\mathrm{Y}_{17.33} \mathrm{O}_{16}\left(\mathrm{BO}_{3}\right)_{4}\left(\mathrm{~B}_{2} \mathrm{O}_{5}\right)_{2}$, peaking at around $760 \mathrm{~cm}^{-1}, 1300 \mathrm{~cm}^{-1}$ and $600 \mathrm{~cm}^{-1}$, respectively, are superimposed with those of the $\left(\mathrm{B}_{2} \mathrm{O}_{5}\right)^{4-}$ group and a clear attribution cannot be made. Due to the overlap between $\left(\mathrm{BO}_{3}\right)^{3-}$ and $\left(\mathrm{B}_{2} \mathrm{O}_{5}\right)^{4-}$ vibration modes in the matrix $\mathrm{Y}_{17.33} \mathrm{~B}_{8} \mathrm{O}_{38}$, it is quite complicated to attribute all the transitions to the different modes but these observations are in good agreement with the data reported by Lin et al. [11].

\subsection{Infrared luminescence}

The two $4 \mathrm{f}$ levels of the ytterbium ion are split by the crystal field in four Stark levels for the ground state ${ }^{2} \mathrm{~F}_{7 / 2}$, and three Stark levels for the excited state ${ }^{2} F_{5 / 2}$. These levels will be labeled from 1 to 4 for the ground state and $5-7$ for the excited state (see inset of Fig. 2). At room temperature, the spectra are generally too complicated to be interpreted: a maximum of 12 transitions (for each site) can occur because of the thermal distribution of electron population in the Stark levels. This phenomenon can be avoided by low temperature measurements. Then, a strong interaction of the ytterbium ion with lattice vibrations must be considered [8]. This electron-phonon coupling results in additional vibronic transitions in the spectra.

All the measurements were performed on powdered sample. No absorption or excitation spectrum in the infrared range has been obtained. Fig. 2 represents the emission spectra of the two 1\% ytterbium doped matrices for an excitation at $932 \mathrm{~nm}$. The oxyborate $\mathrm{LiY}_{6} \mathrm{O}_{5}\left(\mathrm{BO}_{3}\right)_{3}: \mathrm{Yb}^{3+}$ shows three intense lines at $974.5 \mathrm{~nm}, 975.5 \mathrm{~nm}$ and $977 \mathrm{~nm}$. At higher wavelengths, the intensity decreases down to $1080 \mathrm{~nm}$. However a maximum can be distinguished at $1025 \mathrm{~nm}$.

\begin{tabular}{|c|c|c|c|c|c|c|c|}
\hline \multicolumn{8}{|c|}{ Energy of the vibrational modes $\left(\mathrm{cm}^{-1}\right)$} \\
\hline \multicolumn{2}{|l|}{$\underline{v_{1}}$} & \multicolumn{2}{|l|}{$\underline{v_{2}}$} & \multicolumn{2}{|l|}{$v_{3}$} & \multicolumn{2}{|l|}{$v_{4}$} \\
\hline Raman & IR & Raman & IR & Raman & $\mathbb{R}$ & Raman & IR \\
\hline & & & 746 & & 1197 & $517(2)$ & \\
\hline 935 & 937 & 775 & 777 & 1292 & 1250 & $530(?)$ & 629 \\
\hline \multirow[t]{2}{*}{950} & & & 795 & & 1300 & 570 & 652 \\
\hline & & & & & 1360 & 593 & \\
\hline
\end{tabular}

The compound $\mathrm{Y}_{17.33} \mathrm{~B}_{8} \mathrm{O}_{38}: \mathrm{Yb}^{3+}$ presents the same behavior with a transition located at $983 \mathrm{~nm}$ and a group of intense lines peaking at $980 \mathrm{~nm}, 983 \mathrm{~nm}$ and $986 \mathrm{~nm}$. A maximum is observed at $1012 \mathrm{~nm}$ and the total emission ranges from $975 \mathrm{~nm}$ to $1090 \mathrm{~nm}$.

Four principal transitions are expected from the level 5 of the ${ }^{2} F_{5 / 2}$ multiplet and in that case only the intense one can clearly be attributed to the $5 \rightarrow 1$ transition. In the studied compounds, the multiplicity of these lines reflects the versatility of the ytterbium environment. The difference in the local crystal field leads to different splitting of the stark components of the ytterbium ions. The lowest energy part of the spectra cannot be explained because of the broadening of the lines (electron-phonon coupling) and the superposition with emission lines from other levels.

The low temperature decreases the line widths but not enough to obtain well-resolved spectra. The inset represents the $5 \rightarrow 1$ transitions. It might be possible that the high number of transitions detected for $\mathrm{Y}_{17.33} \mathrm{~B}_{8} \mathrm{O}_{38}: \mathrm{Yb}^{3+}$ reveals the presence of small quantities of impurities. 
The infrared emission of the $1 \%$-doped samples was also recorded under excitation in the charge transfer state of the ytterbium ion in the ultraviolet [15]. The very strong absorption at these wavelengths ensures a small penetration of the excitation beam in the sample. The emission of the surface is less affected by re-absorption like radiation trapping than the emission observed after an excitation in the infrared range [16]. The position of the charge transfer bands is correlated with the environments of the rare earth element and the nature of the ligand in the coordination polyhedra. Several excitation wavelengths were selected. Emission spectra at $30 \mathrm{~K}$ are reported in Fig. 3 for $1 \%$ ytterbium doped samples.

For an excitation in the charge transfer band at low temperature, only three lines associated with the $5 \rightarrow 1$ transitions are visible for $\mathrm{LiY}_{6} \mathrm{O}_{5}\left(\mathrm{BO}_{3}\right)_{3}: \mathrm{Yb}^{3+}$ whereas four groups of lines can be distinguished for $\mathrm{Y}_{17.33} \mathrm{~B}_{8} \mathrm{O}_{38}: \mathrm{Yb}^{3+}$ (see inset of Fig. 3). Each of these transitions has been named with a Greek letter in order to simplify the description. For $\mathrm{LiY}_{6} \mathrm{O}_{5}\left(\mathrm{BO}_{3}\right)_{3}: \mathrm{Yb}^{3+}$, the excitation at $230 \mathrm{~nm}$ leads to the maximum of emission intensity attributed to the $y$ lines. For an excitation at $215 \mathrm{~nm}$, the same lines are observed but with different intensity ratio. The $\beta$ transition is then the most intense. This last line disappears for an excitation at $250 \mathrm{~nm} . \mathrm{Y}_{17.33} \mathrm{~B}_{8} \mathrm{O}_{38}: \mathrm{Yb}^{3+}$ presents four groups of lines with an increasing ratio for the $\delta, \varepsilon, \zeta$ groups for an excitation at $230 \mathrm{~nm}$. An excitation at $220 \mathrm{~nm}$ leads to the emission of the $\zeta$ and $\eta$ groups, and an excitation at $250 \mathrm{~nm}$ favors the $\delta$ group. For each spectrum, the obtained intensity ratio for an excitation of the charge transfer bands is different to that observed for an excitation of the ${ }^{2} F_{5 / 2}$ level (see Fig. 2). This is probably due to the different values of absorption cross sections in the infrared range $\left(\lambda_{\text {exc }}=932 \mathrm{~nm}\right)$ for ytterbium ions located in different crystallographic sites. Because of the difficulty to obtain absorption spectra for powders in the infrared range, we were not able to quantify this difference. As for a $4 \mathrm{f}-4 \mathrm{f}$ excitation, the lowest energy part of the spectra cannot be identified due to their complexity.

Excitation spectra (Fig. 4) were performed in the ultraviolet range for the most intense emission lines in order to discriminate the charge transfer bands of ytterbium ions. The spectra were normalized on the $y$ transition at $230 \mathrm{~nm}$ for $\mathrm{LiY}_{6} \mathrm{O}_{5}\left(\mathrm{BO}_{3}\right)_{3}: \mathrm{Yb}^{3+}$ and on the $\eta$ transition at $225 \mathrm{~nm}$ for $\mathrm{Y}_{17.33} \mathrm{~B}_{8} \mathrm{O}_{38}: \mathrm{Yb}^{3+}$, preserving the intensity ratio between the spectra issued from different emission lines. For both matrices, some of the $5 \rightarrow 1$ transitions possess a more efficient excitation at the higher wavelengths (about $250 \mathrm{~nm}$ ): the a lines for $\mathrm{LiY}_{6} \mathrm{O}_{5}\left(\mathrm{BO}_{3}\right)_{3}: \mathrm{Yb}^{3+}$ and the $\delta$ and $\eta$ ones for $\mathrm{Y}_{17.33} \mathrm{~B}_{8} \mathrm{O}_{38}: \mathrm{Yb}^{3+}$ respectively. According to these data, we can confirm the existence of different charge transfer states. Selective excitations in these bands results in the several emission spectra. Some of them (high energy part of the spectrum) lead to charge transfer emission of ytterbium in the ultraviolet [15] followed by a radiative de-excitation of the

${ }^{2} \mathrm{~F}_{5 / 2}$ level on the ${ }^{2} \mathrm{~F}_{7 / 2}$ level in the infrared range (this work). Excitation at high wavelengths (around $250 \mathrm{~nm}$ ) leads to only infrared emission after non radiative transition from the charge transfer band to the ${ }^{2} \mathrm{~F}_{5 / 2}$ level.

Emission lines selected for excitation measurements are attributed to several zero-phonon transitions $(5 \rightarrow 1)$. These lines are not vibronic replica because they conduct to strongly different excitation spectra for both compounds. The gap between these IR transitions, well defined at low temperature, is the result of crystal field strength variations between different ytterbium environments. IR excitation spectra in the UV, issued from zero-phonon lines, are representative of specific ytterbium environments. The environments strongly vary in these compounds giving rise to several zerophonon lines and showing successive charge transfer bands with different de-excitation behavior. Unfortunately no precise attribution could be made between ytterbium crystallographic sites and charge transfer bands.

Fig. 5 represents the excitation spectra for an UV and IR emission of ytterbium in these two matrices at low temperature compared to the diffuse reflectance spectra recorded at room temperature. The absorption bands associated with the infrared emission are shifted to lower energy values compared with the absorption bands of the UV emission. The diffuse reflectance spectra are clearly the envelope of the different charge transfer absorption bands.

\subsection{Lifetime study}

Lifetime measurements have been conducted as a function of concentration of ytterbium ions under excitation at $925 \mathrm{~nm}$, in order to excite the ytterbium in the highest level of the $4 \mathrm{f}$ excited state. The results are plotted on Fig. 6. All decay curves were fitted with a single exponential law with good agreement. The classical lifetime increase due to reabsorption [17] is observed until a substitution rate of $2 \%$ for the two compounds. The overlap between absorption and 
emission spectra makes possible radiative re-absorption. A study made by Milne [18] on a gas medium but transposable to transparent solid state materials, showed that such increase should be observed for the diffusion of a radiation along a propagation direction. From $2 \%$ of substitution $\left(4.2 \times 10^{20}\right.$ ions $/ \mathrm{cm}^{3}$ for $\mathrm{LiY}_{6} \mathrm{O}_{5}\left(\mathrm{BO}_{3}\right)_{3}: \mathrm{Yb}^{3+}$ and $4.3 \times 10^{20}$ ions $/ \mathrm{cm}^{3}$ for $\left.\mathrm{Y}_{17.33} \mathrm{~B}_{8} \mathrm{O}_{38}: \mathrm{Yb}^{3+}\right)$ up to $20 \%\left(42.1 \times 10^{20}\right.$ ions $/ \mathrm{cm}^{3}$ for $\mathrm{LiY}_{6} \mathrm{O}_{5}\left(\mathrm{BO}_{3}\right)_{3}: \mathrm{Yb}^{3+}$ and $43 \times 10^{20}$ ions $/ \mathrm{cm}^{3}$ for $\mathrm{Y}_{17.33} \mathrm{~B}_{8} \mathrm{O}_{38}: \mathrm{Yb}^{3+}$ ) the lifetimes decrease down to about $400 \mu \mathrm{s}$. This strong decrease of the lifetime is due to concentration quenching. The increase of the concentration decreases the distance between ytterbium ions and resonant transfers resulting in a migration of energy can occur. This energy is either released by spontaneous emission or quenched by a defect or an impurity in the lattice (which is the more probable case when concentration increases). Finally this quenching mechanism shortens the lifetime.

A recent model [17], based on the Milne's approach of radiation trapping, was developed to interpret concentration quenching processes in ytterbium doped sesquioxides. This model takes into account either a fast diffusion towards intrinsic defects or a limited diffusion process, being the probability of both quenching and transfer of the same magnitude. This particular case can be simply explained by the high probability of resonant transfers between the ytterbium ion and other rare earth elements (such as erbium). It has been observed that the limited diffusion process fits better experimental data for other compounds [19] and [20] than in our case. This model links the lifetime $\tau$ as a function of the ion concentration $N\left(\right.$ ions $\left./ \mathrm{cm}^{3}\right)$ :

$$
\tau(N)=\frac{\tau_{0}(1+\sigma N l)}{1+\left(\frac{9}{2 \pi}\right)\left(\frac{N}{N_{0}}\right)^{2}}
$$

where $T_{0}(\mathrm{~ms})$ is the pure radiative lifetime, $\sigma\left(\mathrm{cm}^{2}\right)$ the transition cross section, I $(\mathrm{cm})$ the average absorption length, and $N_{0}$ (ions $/ \mathrm{cm}^{3}$ ) the critical concentration.

The $T_{0}, \sigma l$ and $N_{0}$ parameters were considered as variables. The best fits (see Fig. 6) have been obtained with the following parameters: $T_{0}=1.23 \mathrm{~ms}$ and $T_{0}=0.72 \mathrm{~ms}, \quad \sigma \mathrm{l}=8.8 \times 10^{-22} \mathrm{~cm}^{3}$ and $\sigma \mathrm{I}=2.3 \times 10^{-21} \mathrm{~cm}^{3}$ and finally $N_{0}=1.47 \times 10^{21}$ ions $/ \mathrm{cm}^{3}$ and $N_{0}=1.15 \times 10^{21}$ ions $/ \mathrm{cm}^{3}$ for $\mathrm{LiY}_{6} \mathrm{O}_{5}\left(\mathrm{BO}_{3}\right)_{3}: \mathrm{Yb}^{3+}$ and for $\mathrm{Y}_{17.33} \mathrm{~B}_{8} \mathrm{O}_{38}: \mathrm{Yb}^{3+}$ respectively. The value of $N_{0}$ (the self-quenching parameter) is lower than The $N_{0}$ value found for $\mathrm{CaF}_{2}: \mathrm{Yb}^{3+}\left(N_{0}=7.47 \times 10^{21}\right.$ ions $\left./ \mathrm{cm}^{3}\right)$ [20], $\mathrm{Y}_{2} \mathrm{O}_{3}: \mathrm{Yb}^{3+}\left(N_{0}=1.9 \times 10^{21}\right.$ ions $\left./ \mathrm{cm}^{3}\right)$ [17] and $\mathrm{YAG}: \mathrm{Yb}^{3+}\left(N_{0}=2.3 \times 10^{21}\right.$ ions $\left./ \mathrm{cm}^{3}\right)$ [19] a drawback meaning that the tendency of the material to be self-quenched is higher. In both oxyborates compounds, RE polyhedra are connected by common edges and corners in the three $a-, b$ - and $c$-axis direction; the RE-RE distances are similar in these materials to those observed in the YAG or $\mathrm{Y}_{2} \mathrm{O}_{3}$ matrices. A lower $N_{0}$ value might indicate that the RE polyhedra stacking makes possible a higher overlap of the ytterbium orbitals, leading to the emission quenching.

\subsection{Blue-green luminescence}

The blue-green luminescence of ytterbium doped compounds can be attributed to two phenomena: absorption in the excited state of the infrared emission by thulium or erbium impurities (upconversion process) or cooperative emission. This luminescence has been reported in several matrices: phosphates [21], vanadates [22], sesquioxydes [23] and [24], garnet or fluorite [20]. The luminescence in the visible range was studied under diode excitation at $980 \mathrm{~nm}$ for a $5 \%$ doped compounds (Fig. 7). Two processes were identified: presence of impurities of $\mathrm{Er}^{3+}$ and cooperative luminescence. These emissions have been studied in several other lattices [25], [26], [27] and [28]. Firstly, the concentration of erbium impurity is $5 \mathrm{ppm}$ from the purity certificate of the raw material $\mathrm{Yb}_{2} \mathrm{O}_{3}$. Two photons upconversion from $\mathrm{Yb}^{3+}$ to $\mathrm{Er}^{3+}$ (transitions ${ }^{4} \mathrm{I}_{15 / 2} \rightarrow{ }^{4} \mathrm{I}_{11 / 2}$ followed by ${ }^{4} \mathrm{I}_{11 / 2} \rightarrow{ }^{4} \mathrm{~F}_{7 / 2}$ ) lead to emissions in the green (transitions ${ }^{4} \mathrm{~S}_{3 / 2} \rightarrow{ }^{4} \mathrm{I}_{15 / 2}$ ) and in the red range (transitions ${ }^{4} \mathrm{~F}_{9 / 2} \rightarrow{ }^{4} \mathrm{I}_{15 / 2}$ ). Secondly, the other luminescence centered at $500 \mathrm{~nm}$ is attributed to cooperative luminescence. A simultaneous de-excitation of two neighbor ytterbium ions gives rise to an emission from a virtual level located at about $20,000 \mathrm{~cm}^{-1}$. This emission was observed for the first time by 
Nakazawa in $\mathrm{YbPO}_{4}[21]$ and, Ovsyankin [28] showed that a good approximation of this spectrum is given by the convolution product of the infrared spectrum:

$$
G(2 \bar{v})=\int F(\bar{v}) F\left(\bar{v}-\bar{v}^{\prime}\right) d \bar{v}^{\prime}
$$

where $G$ and $F$ are the visible and infrared spectra, respectively and $\bar{v}$ and $\bar{v}$ wavenumbers in the infrared range.

The insets on Fig. 7 correspond to the convolution product of the infrared emission for an excitation at $230 \mathrm{~nm}$ (dotted line) and at $932 \mathrm{~nm}$ (dashed line) compared to the experimental curve obtained for an excitation at $980 \mathrm{~nm}$ (solid line). The experimental spectra were recorded up to $530 \mathrm{~nm}$ because of the presence of erbium impurities. The spectra and convolution products were normalized to the integrated intensity under the curves. Considering the emission located at higher energy, the best fit can be obtained with the calculated curve for an excitation at $230 \mathrm{~nm}$. This is due to the reabsorption phenomena which modify the shape of the emission spectra at high energy, for an infrared excitation. However, the other part of the spectra is similar to the convolution product for an excitation at $932 \mathrm{~nm}$. In both cases, the line observed at $485 \mathrm{~nm}$ is part of the cooperative emission spectra and are not related to the presence of thulium impurities.

\section{Conclusion :}

In this paper, the infrared luminescence of ytterbium doped oxyborates is reported. For the first time to our knowledge, evidence of the presence of several charge transfer bands with different de-excitation behavior (charge transfer emission or non radiative transition on $4 \mathrm{f}$ levels) in a single compound has been observed. It was also demonstrated that these differences between charge transfer bands were related to the nature of the ytterbium environment. The lifetime study revealed the expected evolution when the concentration increases. The radiative lifetime was found to be equal to $1.4 \mathrm{~ms}$ and $1 \mathrm{~ms}$ for $\mathrm{LiY}_{6} \mathrm{O}_{5}\left(\mathrm{BO}_{3}\right)_{3}: \mathrm{Yb}^{3+} 1 \%$ and for $\mathrm{Y}_{17.33} \mathrm{~B}_{8} \mathrm{O}_{38}: \mathrm{Yb}^{3+} 1 \%$, respectively. Finally, it was shown that the blue-green luminescence was the result of two mechanisms: erbium emission at $550 \mathrm{~nm}$ after up-conversion and cooperative luminescence of ytterbium ions.

\section{Acknowledgments}

This investigation was supported by the CNRS. Jean Sablayrolles thanks the CNRS and the Conseil Régional d'Aquitaine for his grant funding.

\section{References}

1. S. Chénais, F. Druon, F. Balembois, G. Lucas-Leclin, P. Georges, A. Brun, M. Zavelani-Rossi, F. Augé, J.P. Chambaret, G. Aka, D. Vivien, Appl. Phys. B: Lasers Opt. 72 (2001) 389.

2. C. Hönninger, R. Paschotta, M. Graf, F. Morier-Genoud, G. Zhang, M. Moser, S. Biswal, J. Nees, A. Braun, G.A. Mourou, I. Johannsen, A. Giesen, W. Seeber, U. Keller, Appl. Phys. B: Lasers Opt. 69 (1999) 3.

3. Y. Zaouter, J. Didierjean, F. Balembois, G. Lucas-Leclin, F. Druon, P. Georges, J., Petit, P. Goldner, B. Viana, Opt. Lett. 31 (1) (2006) 119.

4. F. Druon, F. Balembois, P. Georges, C.R. Physique. 8 (2) (2007) 153.

5. J. Sablayrolles, V. Jubera, J.P. Chaminade, I. Manek-Hönninger, S. Murugan, T. Cardinal, R. Olazcuaga, A. Garcia, F. Salin, Opt. Mater. 27 (2005) 1681.

6. A. Brenier, A. Yoshikawa, K. Lebbou, A. Jouini, O. Aloui-Lebbou, G. Boulon, T. Fukuda, J. Lumin. 126 (2) (2007) 547.

7. M. Delaigue, V. Jubera, J. Sablayrolles, J.-P. Chaminade, A. Garcia, I. Manek-Hönninger, Appl. Phys. B B87 (2007) 693.

8. A. Ellens, H. Andres, M.L.H. ter Heerdt, R.T. Wegh, A. Meijerink, G. Blasse, Phys. Rev. B.: Condens. Matter Mater. Phys 55 (1) (1997) 180.

9. J.P. Chaminade, P. Gravereau, V. Jubera, C. Fouassier, J. Solid State Chem. 146 (1) (1999) 189.

10. J.H. GAO, Chin. J. Struct. Chem. 25 (10) (2006) 1175.

11. J.H. Lin, S. Zhou, L.Q. Yang, G.Q. Yao, M.Z. Su, J. Solid State Chem. 134 (1997) 158.

12. D.C. Bradley, R.C. Mehrotra, D.P. Gaur, Metal Alkoxides, Academic Press, London, 1978. p. 121.

13. Nakamoto (Ed.), Infrared and Raman Spectra of Inorganic and Coordination Compounds, fifth ed., John Wiley, New York, 1997. p. 182.

14. W. Bues, G. Förster, R. Schmitt, Z. Anorg. Allg. Chem. 344 (1966) 148.

15. J. Sablayrolles, V. Jubera, F. Guillen, A. Garcia, Spectrochim. Acta Part A: Mol. Biomol. Spectrosc. 69 (2008) 1010.

16. J. Sablayrolles, V. Jubera, F. Guillen, R. Decourt, M. Couzi, A. Garcia, Opt. Commun. 280 (2007) 103. 
17. F. Auzel, G. Baldacchini, L. Laversenne, G. Boulon, Opt. Mater. 24 (2003) 103.

18. E.A. Milne, J. London, J. London Math. Soc. 1 (1926) 40.

19. C. Goutaudier, K. Lebbou, Y. Guyot, M. Ito, H. Canibano, A. El Hassouni, L. Laversenne, M.T. Cohen-Adad, G. Boulon, Ann. Chim. Sci. Mat. 28 (6) (2003) 73.

20. M. Ito, C. Goutaudier, Y. Guyot, K. Lebbou, T. Fukuda, G. Boulon, J. Phys.: Condens. Matter 16 (2004) 1501.

21. E. Nakazawa, S. Shionoya, Phy. Rev. Lett. 25 (25) (1970) 1710.

22. P. Goldner, B. Schaudel, M. Prassas, Phys. Rev. B 65 (5) (2002) 054103.

23. G. Boulon, L. Laversenne, C. Goutaudier, Y. Guyot, M.T. Cohen-Adad, J. Lumin. 102-103 (2003) 417.

24. Y. Guyot, R. Moncorgé, L.D. Merkle, A. Pinto, B. Mclntosh, H. Verdun, Opt. Mater. 5 (1996) 127.

25. F. Auzel, D. Pecile, C.R. Acad. Sci., Sér. B 277 (1973) 155.

26. F. Auzel, Ann. Télécommun. 24 (1969) 363.

27. F. Auzel, C.R. Acad. Sci., Sér. B 263 (1966) 819.

28. V.V. Ovsyankin, in: A.A. Kaplyanskii, R.M. MacFarlane (Eds.), Spectroscopy of Solids Containing Rare Earth lons, Elsevier Science Publishers, Amsterdam, 1987, p. 447 (Chapter 7). 
Figures :
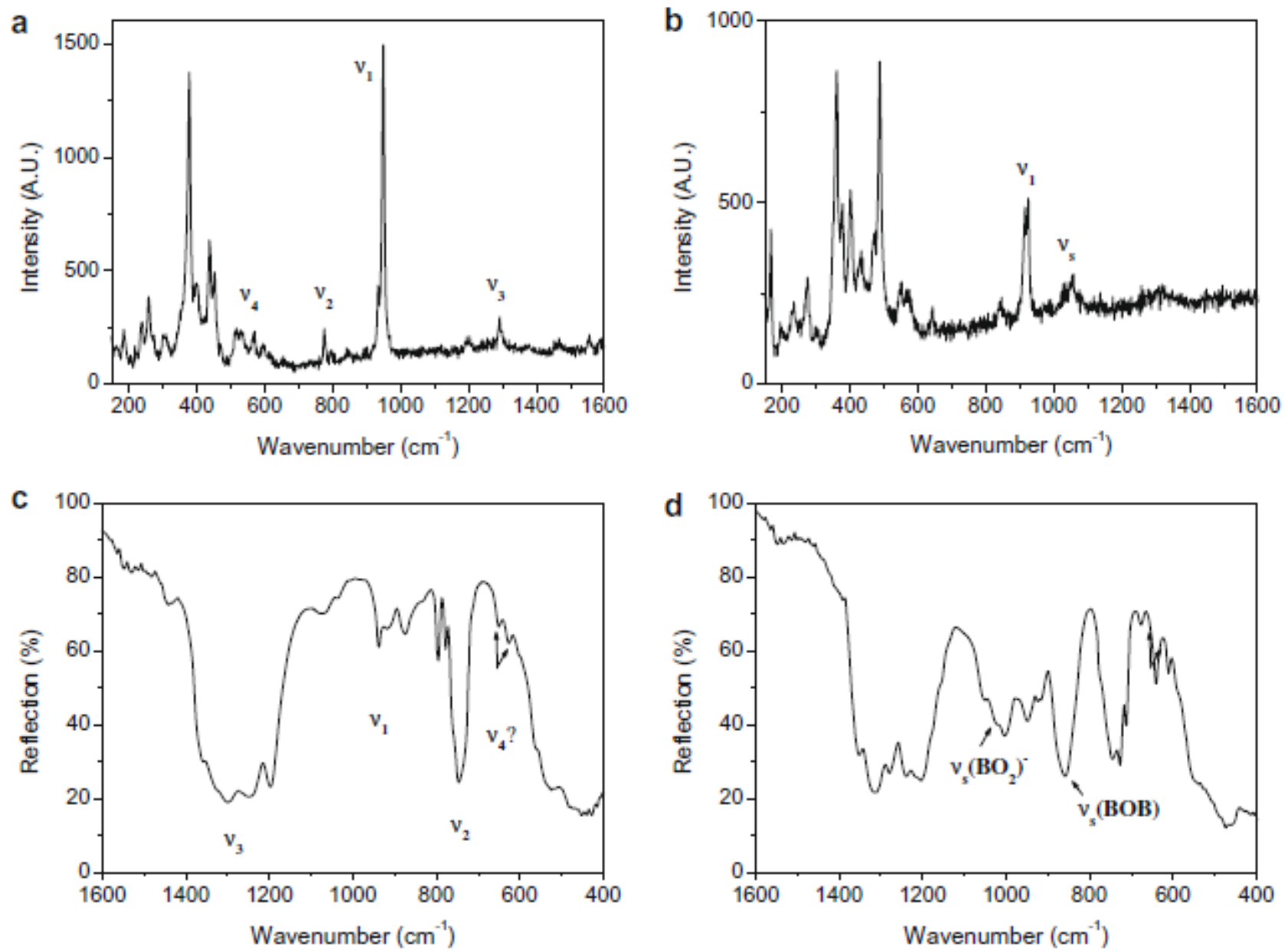

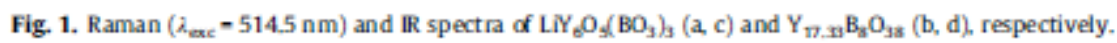



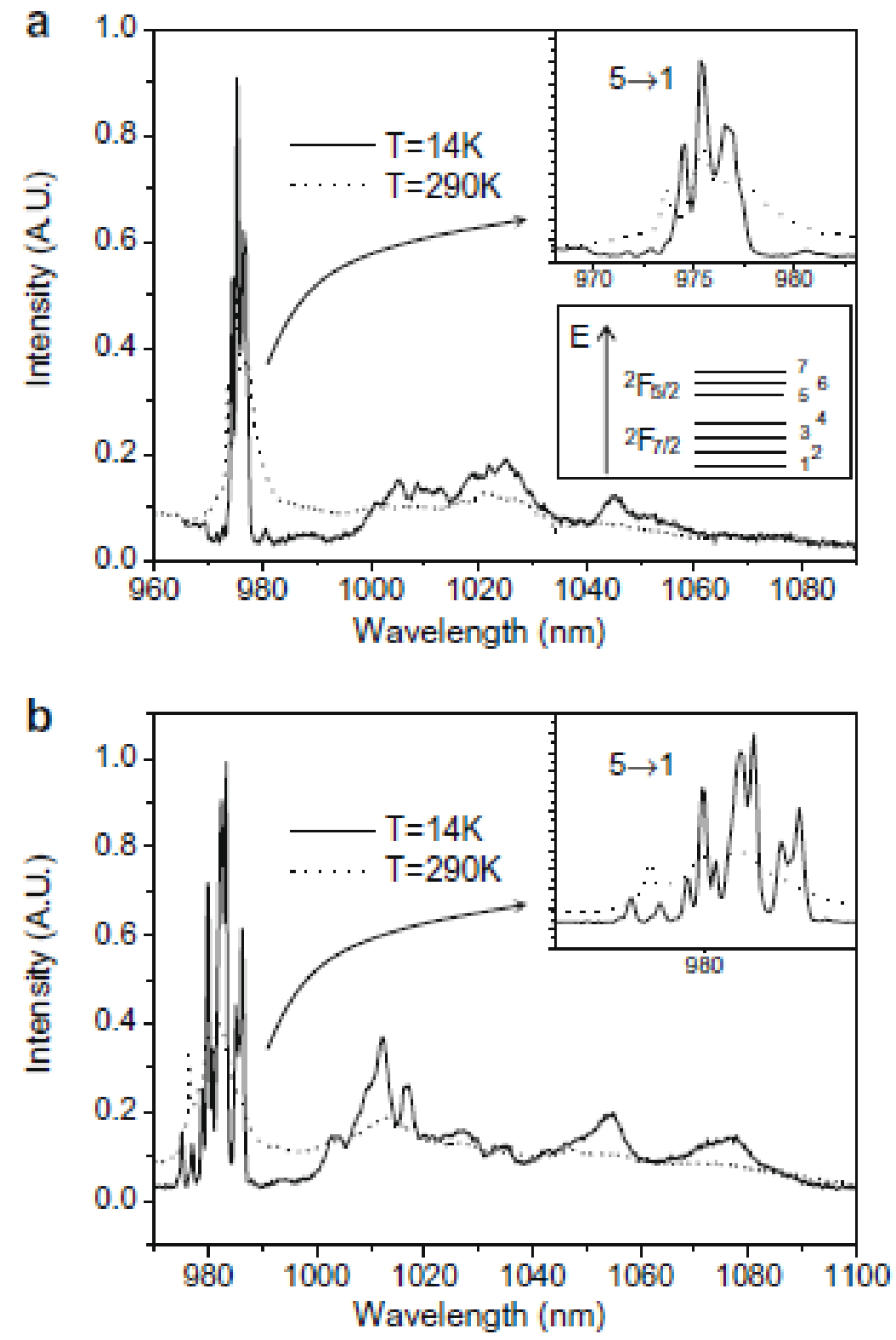

Fig. 2. Emission spectra of $\mathrm{LY}_{6} \mathrm{O}_{9}\left(\mathrm{BO}_{3}\right)_{3}: \mathrm{Yb}^{3+} 1 \mathrm{x}(\mathrm{a})$ and $\mathrm{Y}_{1733} \mathrm{~B}_{\mathrm{a}} \mathrm{O}_{3 \mathrm{~s}}: \mathrm{Yb}^{3+} 1 \mathrm{r}$ (b) for hess $-932 \mathrm{~nm}$ at $14 \mathrm{~K}$ (solid line) and $290 \mathrm{~K}$ (dotted line). Insets zoom of the $5 \rightarrow 1$ zero lines transitions and schematic energy diagram of the Stark components. 

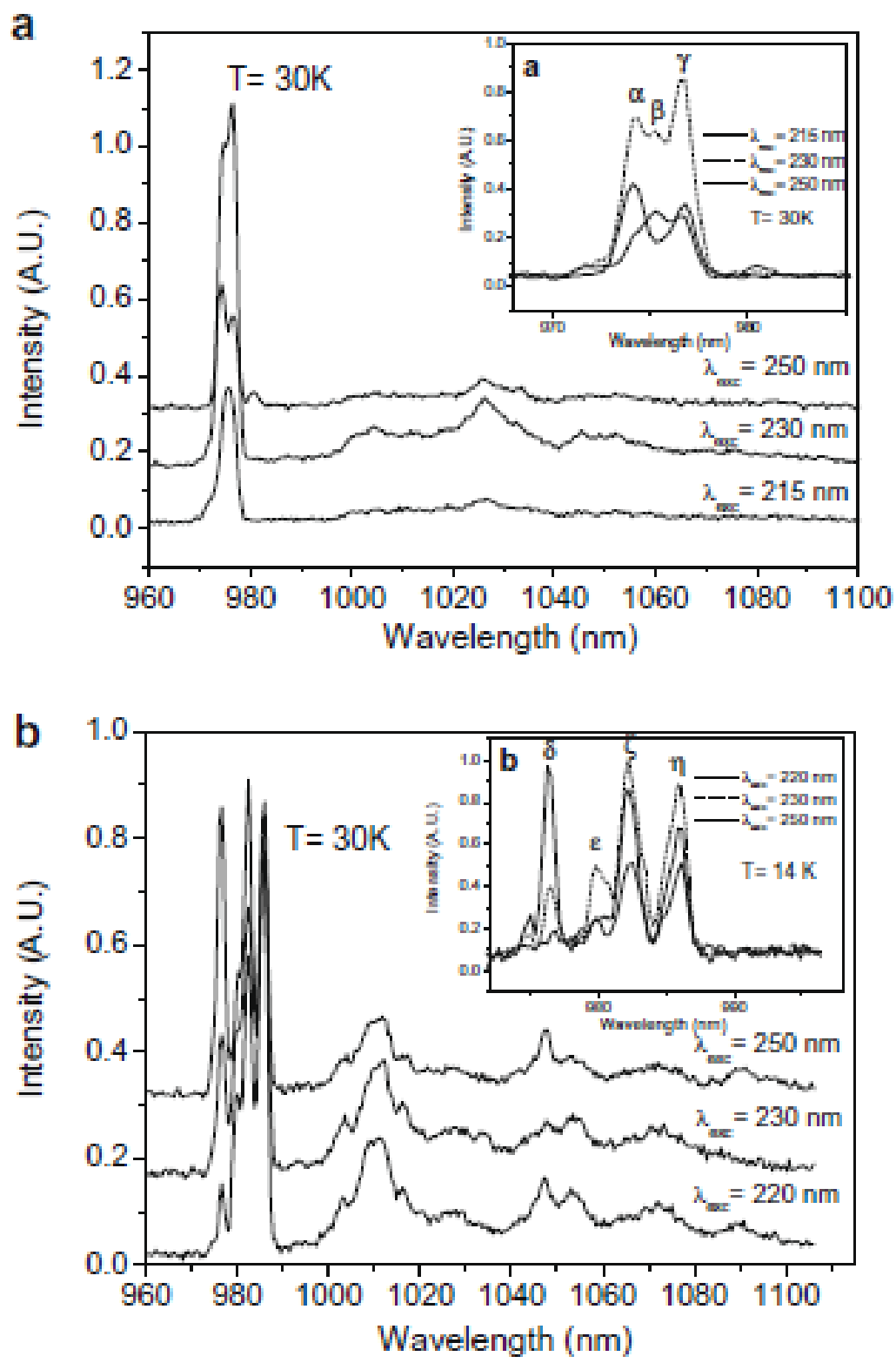

Fig. 3. Emission spectra of $\mathrm{LY}_{6} \mathrm{O}_{5}\left(\mathrm{BO}_{3}\right)_{3}: \mathrm{Yb}^{3+} 1 \mathrm{x}(\mathrm{a})$ and $\mathrm{Y}_{1733} \mathrm{~B}_{3} \mathrm{O}_{38}: \mathrm{Yb}^{3+} 1 \mathrm{\%}$ (b) for excitation in the ultraviolet at bw temperature Insets zoom of the $5 \rightarrow 1$ zero lines transitions. 

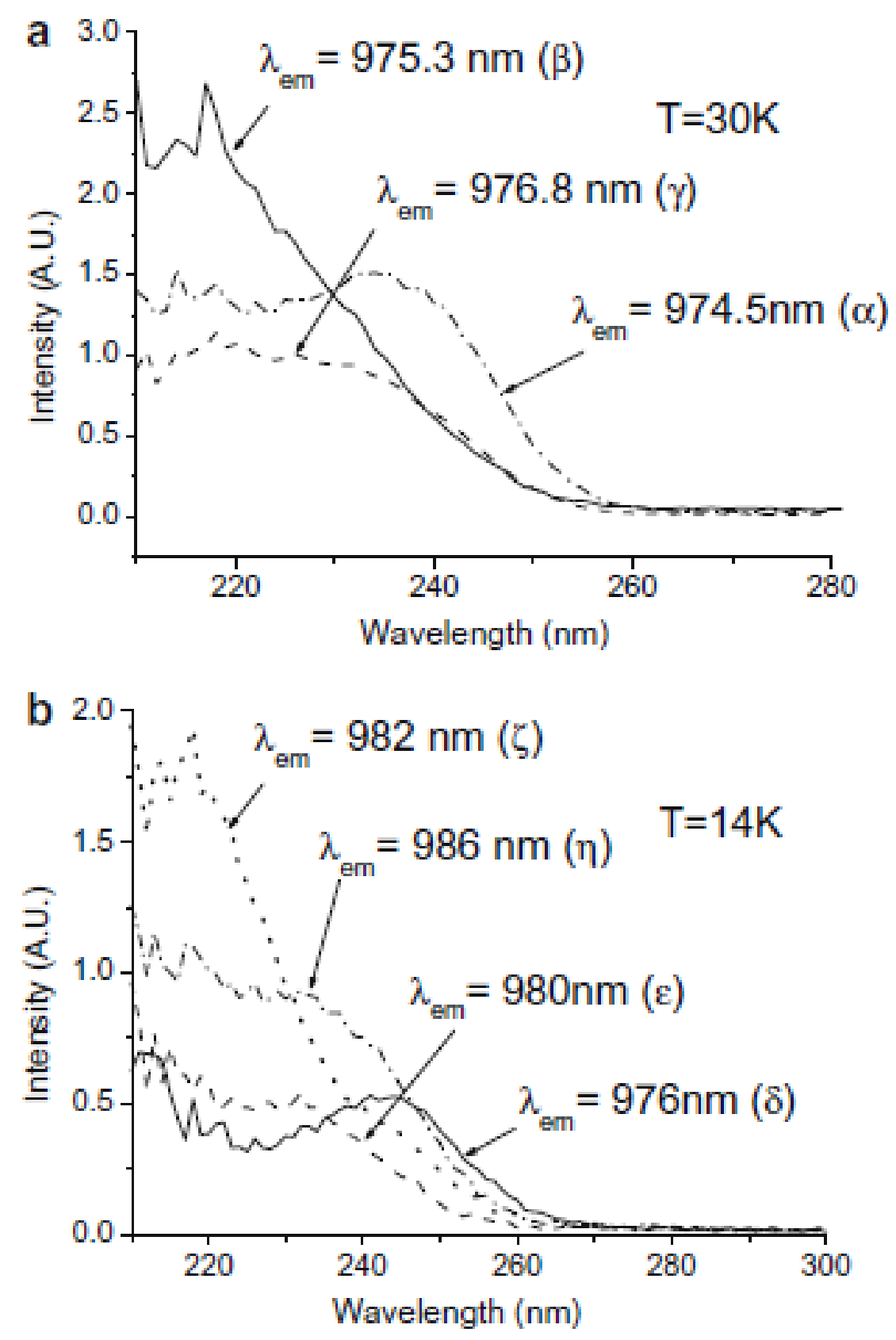

Fig. 4. Excitation spectra of $\mathrm{LiY}_{6} \mathrm{O}_{3}\left(\mathrm{BO}_{3}\right)_{3}: \mathrm{Yb}^{3 *} 1 \mathrm{x}$ (a) and $\mathrm{Y}_{1733} \mathrm{~B}_{3} \mathrm{O}_{38}: \mathrm{Yb}^{3 *} 1 \%$ (b) for different IR emission lines at low temperature. 

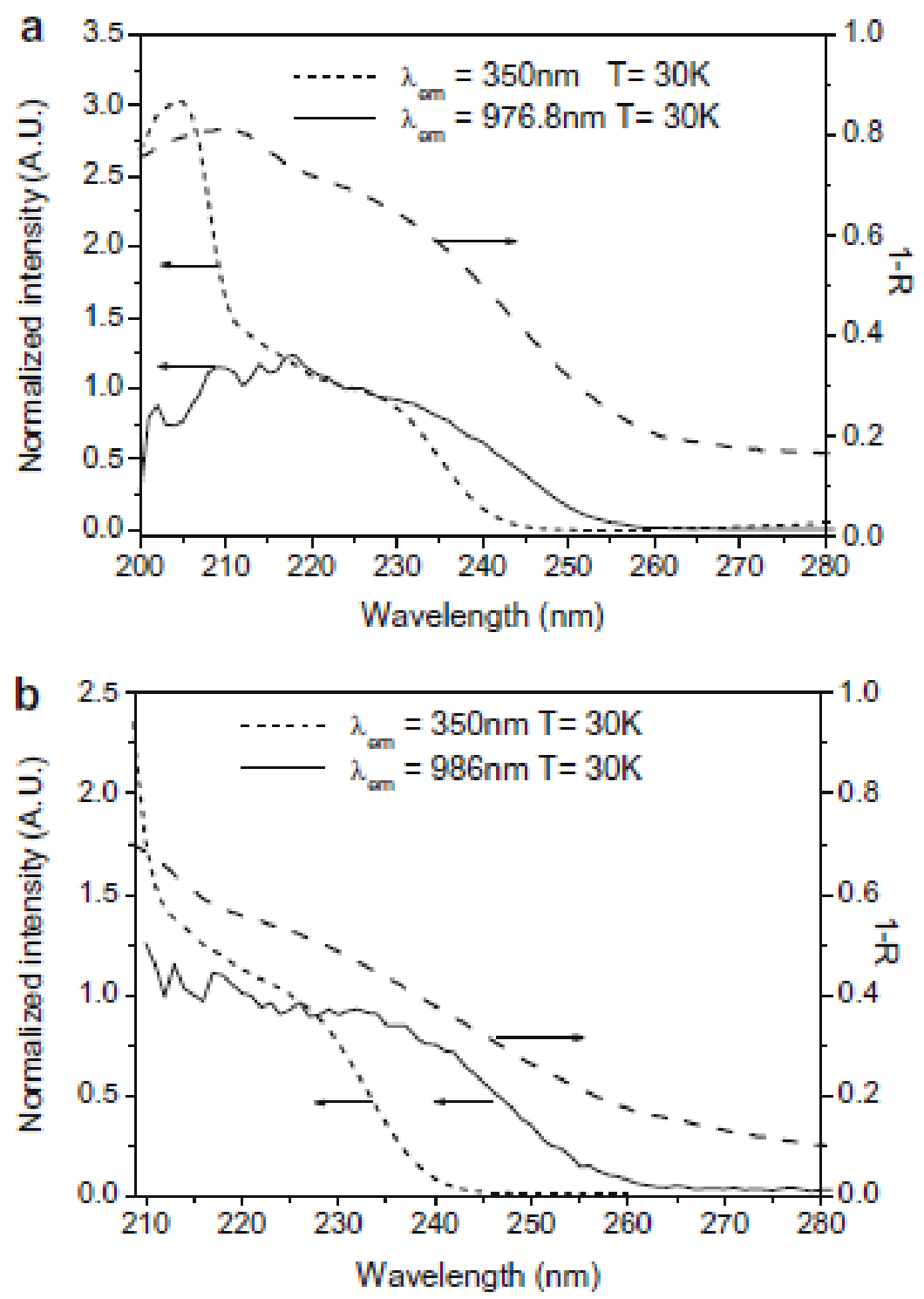

Fig. 5. Excitation spectra of $\mathrm{LY}_{6} \mathrm{O}_{5}\left(\mathrm{BO}_{3}\right)_{3}: \mathrm{Yb}^{3 *} 1 \%$ (a) and $\mathrm{Y}_{\pi 7 . \mathrm{s}} \mathrm{B}_{8} \mathrm{O}_{3 \mathrm{~s}}$ : $\mathrm{Yb}^{3 *} 1 \%$ (b) for IR and UV (CTB) emission at low temperature (solid and dotted line) and reflectance spectra at room temperature. 

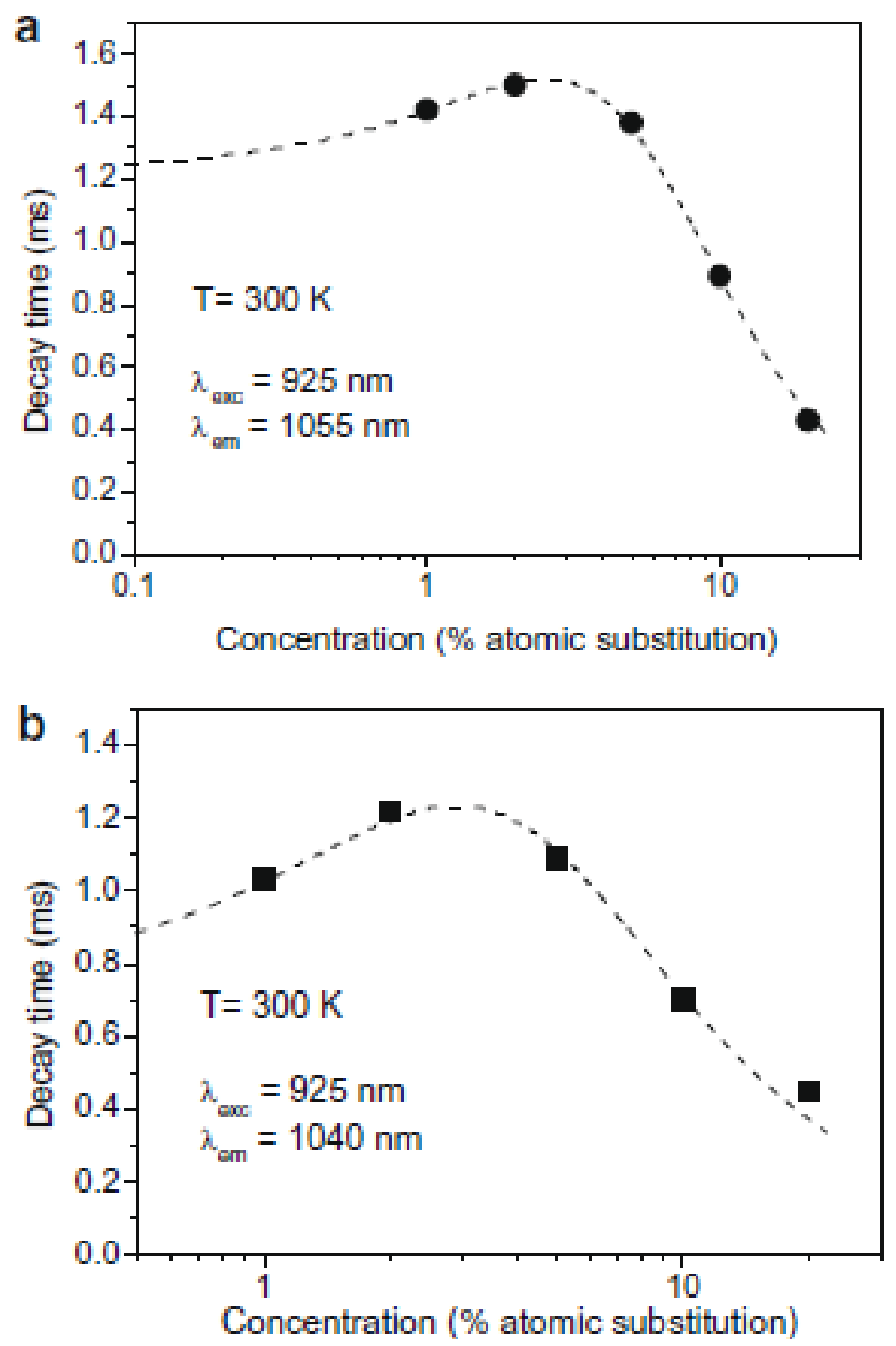

Fig. 6. Decay time of $\mathrm{LY}_{6} \mathrm{O}_{5}\left(\mathrm{BO}_{3}\right)_{3}: \mathrm{Yb}^{3 *}$ (a) and $\mathrm{Y}_{1233} \mathrm{~B}_{4} \mathrm{O}_{\mathrm{s}}: \mathrm{Yb}^{3 *}$ (b) at room temperature (scatter) and simulation of the experimental behavior (dashed line) as a function of ytterbium ions concentration. 

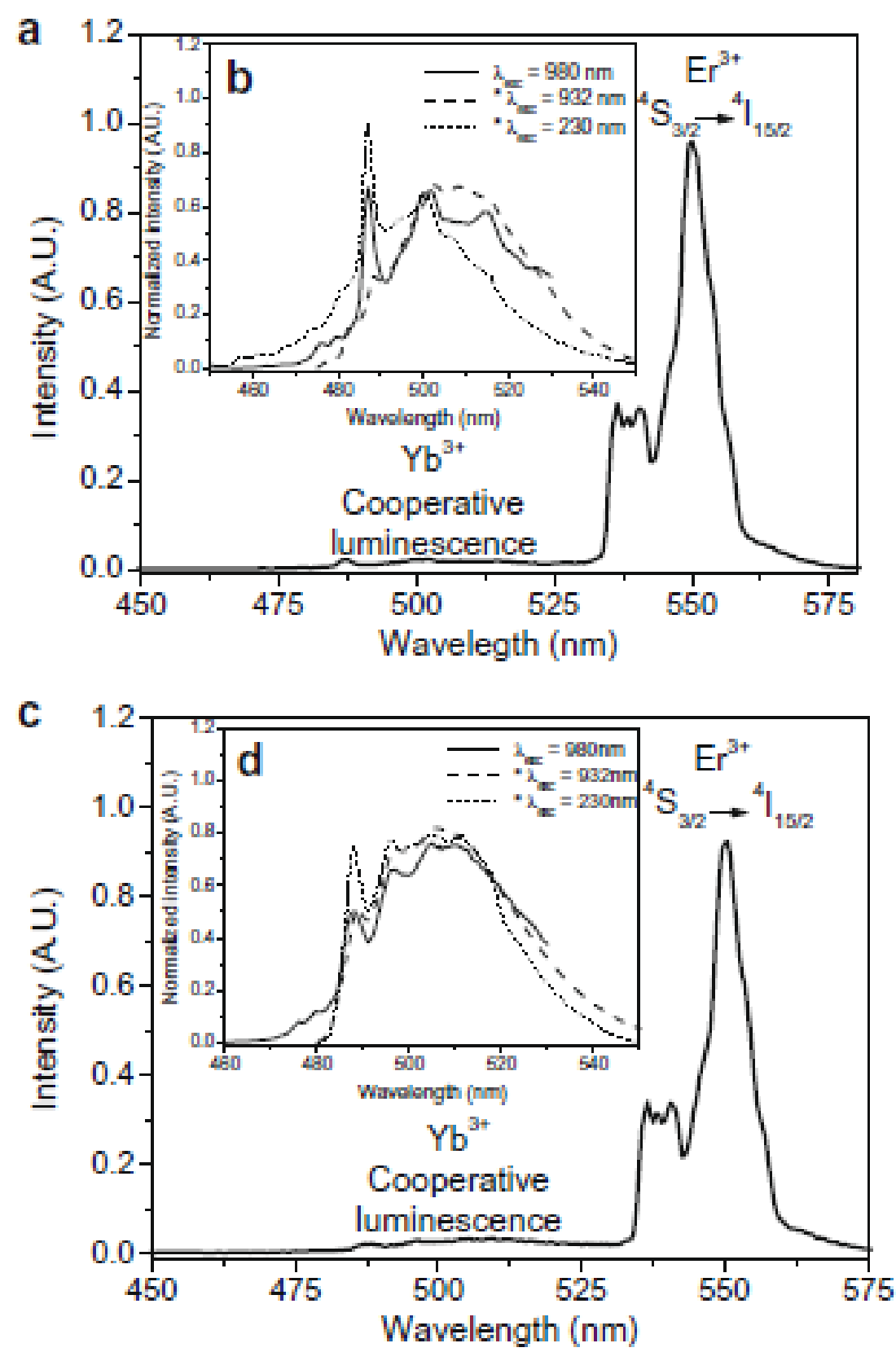

Fig. 7. Visible emission spectra of $\mathrm{LIY}_{6} \mathrm{O}_{5}\left(\mathrm{BO}_{3}\right)_{3}: \mathrm{Yb}^{3 *} 5 \%$ (a) and $\mathrm{Y}_{1733} \mathrm{~B}_{8} \mathrm{O}_{33}: \mathrm{Yb}^{3 *} 5 \%$ (c) for $\lambda=-980 \mathrm{~nm}$ at $300 \mathrm{~K}$ (solid line). Insets (b) (d): Convolution product of the infrared emission spectra for excitation at $230 \mathrm{~nm}$ (dotted line) and $932 \mathrm{~nm}$ (d ashed line). 